\title{
The association between serum magnesium levels and community-acquired pneumonia 30-day mortality
}

\author{
Roni Nasser ${ }^{1 * \dagger}$, Mohammad E. Naffaa ${ }^{2 \dagger}$, Tanya Mashiach ${ }^{3}$, Zaher S. Azzam ${ }^{1,4}$ and Eyal Braun ${ }^{4,5}$
}

\begin{abstract}
Background: Community acquired pneumonia (CAP) is a common illness affecting hundreds of millions worldwide. Few studies have investigated the relationship between serum magnesium levels and outcomes of these patients. We aimed to study the association between serum magnesium levels and 30-day mortality among patients with CAP.

Methods: Retrospective overview of patients hospitalized with CAP between January 1, 2010 and December 31, 2016. Participants were analyzed retrospectively in order to identify the risk factors for a primary endpoint of 30-day mortality. Normal levels of magnesium levels in our laboratory varies between 1.35 and $2.4 \mathrm{mg} / \mathrm{dl}$.

Results: 3851 patients were included in our cohort. Age $>75$ years, blood urea nitrogen (BUN) $>20 \mathrm{mg} / \mathrm{dl}$, hypoalbuminemia, and abnormal levels of magnesium were all associated with increased risk of 30-day mortality. Normal magnesium levels were associated with the lowest mortality rate (14.7\%). Notably, within the normal levels, high normal magnesium levels $(2-2.4 \mathrm{mg} / \mathrm{dl})$ were correlated with higher mortality rates (30.3\%) as compared to levels that ranged between $1.35-2 \mathrm{mg} / \mathrm{dl}$ (12.9\%). Hypomagnesemia and hypermagnesemia were both associated with excess of 30-day mortality, 18.4 and 50\%, respectively.
\end{abstract}

Conclusion: Hypomagnesemia and hypermagnesemia on admission were associated with an increased rate of 30-day mortality among adult patients hospitalized with CAP. Interestingly, magnesium levels within the upper normal limits were associated with higher mortality.

Keywords: Pneumonia, Hypomagnesemia, Hypermagnesemia, Mortality

\section{Background}

Community acquired pneumonia (CAP) is a common illness affecting hundreds of millions worldwide, with increasing hospital admissions throughout the years mainly due to the aging population. It is a major cause of mortality and morbidity in all age groups, especially elderly, despite the effectiveness of the diverse antibiotic treatment [1-3].

The prognostic scores used in the clinical settings, such as CURB 65 and Pneumonia Severity Index (PSI) are acknowledged as tools to estimate the mortality rates and thus determine the treatment setting, either outpatient or inpatient $[2,4]$.

\footnotetext{
* Correspondence: roni.nasser@gmail.com

${ }^{\dagger}$ Roni Nasser and Mohammad E. Naffaa contributed equally to this work.

'Department of Internal Medicine "B", Ramabm Health Care Campus, HaAliya HaShniya St 8, 3109601 Haifa, Israel

Full list of author information is available at the end of the article
}

Magnesium (Mg) is the second most profound intracellular mineral in the human body. It is essential for energy production, mainly by binding ATP; synthesis of DNA, RNA and proteins. Mg also plays a role in the active transport of calcium and potassium ions across cell membranes, and thus has an essential role for maintaining proper function of the neuromuscular and cardiovascular systems [5].

Magnesium deficiency has been associated with a number of clinical manifestations such as arrhythmias, cardiac insufficiency, sudden death, muscle weakness, bronchospasm, tetany, seizures, as well as hypokalemia, hypocalcaemia, hyponatremia, and hypophosphatemia $[6,7]$. Several studies demonstrated that hypomagnesemia at admission or during ICU stay was associated with guarded prognosis $[8,9]$, and magnesium supplementation was associated with a lower mortality rate [8]. 
Hypermagnesemia, which is less frequent than hypomagnesemia, commonly occurs due to excessive administration of magnesium salts or magnesium-containing drugs, especially in patients with reduced renal function. It may be caused, also, by rapid mobilization from soft tissues in patients with sepsis or trauma, adrenal insufficiency and hypothyroidism. Hypermagnesemia may cause severe symptomatic hypotension, bradycardia and ECG changes like wide QRS [5, 10]. Hypermagnesemia was associated with highest rates of death in critically ill patients [11].

We recently showed that hyperphosphatemia and hypophosphatemia were independently associated with increased 30-days mortality rates in patients with CAP [12].

In this study, we aimed to examine the association between serum magnesium levels on admission and the 30-day mortality in patients with CAP.

\section{Methods}

\section{Study design}

Retrospective overview of patients who were admitted to Rambam Health Care Campus (RHCC), Haifa, Israel, between January 2010 and 31 December 2016. RHCC is a 1000 bed teaching hospital. The patient population is diverse, as RHCC is the major tertiary medical center for all of Northern Israel, serving more than two million residents. According to hospital records, there are 140,000 emergency department visits every year and about 90,000 inpatient admissions. The Rambam Hospital Institutional Review Board approved the study. The approval number is 0597-16-RMB. The need for informed consent was waived because of the retrospective, medical record-based design of the study. The study population included patients 18 years or older with CAP. The diagnosis of pneumonia was based upon the primary diagnosis of pneumonia on the discharge report, within the first twenty-four hours from admission. Exclusion criteria included patients younger than 18 years, those who were transferred from another acute care facilities, hospitalization during the month prior to admission, hospital-acquired pneumonia (HAP) or partial antibiotic treatment.

Patients' data was retrieved and analyzed using Prometheus, RHCC integrated electronic medical records system. The 30-day mortality data were retrieved from Prometheus and the ministry of health. The retrieved data included age, gender; vital signs including blood pressure (BP), systolic and diastolic, heart rate (HR), Oxygen saturation (SO2) respiratory rate (RR), temperature; Comorbidities: history of prior or current malignancies (solid or hematologic), lung disease, smoking status, cardiovascular diseases, kidney diseases, immune deficiency conditions, HIV status, diabetes mellitus, liver cirrhosis, prior neurologic damage, alcohol abuse, intravenous drug abuse and nursing house residence smoking history. The Charlson's comorbidity score was calculated based on data collected; laboratory values (first values within $48 \mathrm{~h}$ ): Hemoglobin $(\mathrm{Hb})$, White blood cell count (WBC), red blood cell distribution width (RDW), $\mathrm{pH}$, partial pressure of carbon dioxide (pCO2), Serum glucose, serum creatinine, sodium, calcium, phosphorus, magnesium, blood urea nitrogen (BUN), and serum albumin.

Hematological values were measured using the Advia 120 Hematology Analyzer (Siemens Healthcare Diagnostics Deerfield, Illinois, USA). Serum glucose, serum creatinine, sodium, calcium, phosphorus, magnesium, blood urea nitrogen (BUN), and serum albumin were measured on admission Using "Dimension" (Siemens Healthcare Diagnostics Deerfield, Illinois, USA). PH, bicarbonate, partial pressure of $\mathrm{CO} 2$ and lactate were measured using GEM premier 3500.

The normal serum magnesium range in our laboratory is $1.35-2.4 \mathrm{mg} / \mathrm{dl}$.

\section{Statistical analysis}

Statistical analysis was performed by using the SPSS statistical package (SPSS, Inc., Chicago, USA) version 21.0.

Quantitative variables are expressed as mean $\pm \mathrm{SD}$. Qualitative variables are expressed as values and percentages. The odds ratio (OR) with $95 \%$ confidence interval (CI) was computed using bivariate logistic regression analysis. The correlation between patients' characteristics and 30-day mortality were evaluated by $P$ values derived from bivariate analysis. Multivariate forward stepwise logistic regression was used to evaluate the relation between patients' features, co-morbidities, laboratory parameters, and 30-day mortality.

Parameters with notable level of significance $(P<0.1)$ of the bivariate association with 30-day mortality were chosen for the multivariate analysis. Bootstrap multivariate analysis was used to evaluate the accuracy of the parameters in the model by estimating standard error, confidence intervals, and bias. The area under curve (AUC) was applied in the model to assess the prognostic value of magnesium. $P$ values equals or less than 0.05 was acknowledged as statistically significant.

\section{Results}

Between January 1, 2010 and December 31, 2016, 4708 patients were diagnosed with CAP at discharge. 3851 patient had magnesium levels within $48 \mathrm{~h}$. Fifty five percent were males. Median age was 72 years old. The 30-day mortality was $15.2 \%$ (587 patients) and almost the same each year during the study.

Hypomagnesemia $(\leq 1.35 \mathrm{mg} / \mathrm{dl})$ was detected in 240 patients $(6 \%)$ and hypermagnesemia $(\geq 2.4 \mathrm{mg} / \mathrm{dl})$ in 26 patients (1\%), while 3581 patients (93\%) were normomagnesemic $(1.35-2.4 \mathrm{mg} / \mathrm{dl})$. 
Table 1 shows bivariate analysis of the association between patients' characteristics, laboratory parameters and 30-day mortality.

Figure 1 demonstrates that hypomagnesemia and hypermagnesemia were associated with higher 30 -day mortality rates (18.4\%, OR 1.52, CI 1.13-2.03 and 50\% OR 5.78, CI $2.66-12.53$ respectively) compared to normomagnesemic group (14.8\%). Thirty-day mortality rate was significantly higher (30.3\%, OR 2.92, CI 2.27-3.75) in patients with magnesium levels within the upper normal limit (2-2.4 $\mathrm{mg} / \mathrm{dl}$ ) compared to the levels $1.35-2 \mathrm{mg} / \mathrm{dl}$ which has mortality rate of $12.9 \%$.

\section{Relationship between phosphorous levels, magnesium} levels and 30-day mortality

As shown in Table 2, abnormal magnesium levels were associated with high mortality rates regardless of all phosphorus levels.
Relationship between blood urea nitrogen (BUN), magnesium, albumin, age and mortality

As shown in Fig. 2, the association between serum magnesium levels and 30-day mortality due to community acquired pneumonia outcome was maintained after adjustment for BUN, albumin and age.

\section{Multivariate analysis of factors associated with 30-day mortality}

As shown in Table 3, in multivariate regression analysis, variables associated with increased risk of 30-day mortality include age $>75$ years, BUN $>20 \mathrm{mg} / \mathrm{dl}$, albumin $<3$ $\mathrm{g} / \mathrm{dl}$, inorganic phosphorus levels $>4.5 \mathrm{mg} / \mathrm{dl}$ and abnormal levels of magnesium (hypermagnesemia, including high normal levels and hypomagnesemia).

In bootstrap multivariate analysis we show that all variables, including magnesium, which were significant in multivariate analysis were also significant in the model. The

Table 1 Bivariate analysis of parameters associated with 30 days mortality

\begin{tabular}{|c|c|c|c|c|c|c|c|c|c|}
\hline & & \multicolumn{2}{|l|}{ Total } & \multicolumn{2}{|c|}{30 day mortality } & \multirow[b]{2}{*}{$P$ value } & \multirow[b]{2}{*}{ OR } & \multirow{2}{*}{$\begin{array}{l}95 \% \mathrm{Cl} \\
\text { lower }\end{array}$} & \multirow[b]{2}{*}{ Upper } \\
\hline & & Number & Percent (\%) & Number & $\overline{\text { Percent } \%}$ & & & & \\
\hline & Total patients & 3851 & & 587 & $15.2 \%$ & & & & \\
\hline \multirow[t]{5}{*}{ Age (years) } & $<65$ & 1215 & $32 \%$ & 81 & $6.7 \%$ & 0.000 & 1.00 & 0.00 & 0.00 \\
\hline & $65-69$ & 354 & $9 \%$ & 31 & $8.8 \%$ & 0.180 & 1.34 & 0.87 & 2.07 \\
\hline & 70-79 & 947 & $25 \%$ & 156 & $16.5 \%$ & 0.000 & 2.76 & 2.08 & 3.67 \\
\hline & $80-85$ & 545 & $14 \%$ & 114 & $20.9 \%$ & 0.000 & 3.70 & 2.73 & 5.03 \\
\hline & $>85$ & 790 & $21 \%$ & 205 & $25.9 \%$ & 0.000 & 4.91 & 3.72 & 6.47 \\
\hline \multirow[t]{2}{*}{ Gender } & Male & 2136 & $55 \%$ & 339 & $15.9 \%$ & 0.226 & 1.12 & 0.93 & 1.33 \\
\hline & Female & 1715 & $45 \%$ & 248 & $14.5 \%$ & 0.000 & 1.00 & 0.00 & 0.00 \\
\hline \multirow[t]{4}{*}{ Albumin (g/dl) } & $3.5-4$ & 374 & $10 \%$ & 8 & $2.1 \%$ & 0.000 & 1.00 & 0.00 & 0.00 \\
\hline & $3-3.4$ & 728 & $19 \%$ & 39 & $5.4 \%$ & 0.016 & 2.59 & 1.20 & 5.60 \\
\hline & $2-3$ & 2649 & $69 \%$ & 303 & $14.2 \%$ & 0.000 & 7.59 & 3.73 & 15.46 \\
\hline & $<2$ & 520 & $14 \%$ & 220 & $42.3 \%$ & 0.000 & 33.55 & 16.30 & 69.05 \\
\hline \multirow[t]{4}{*}{ BUN (mg/dl) } & $<20$ & 1690 & $44 \%$ & 108 & $6.4 \%$ & 0.000 & 1.00 & 0.00 & 0.00 \\
\hline & $20-39$ & 1479 & $38 \%$ & 239 & $16.2 \%$ & 0.000 & 2.82 & 2.22 & 3.59 \\
\hline & $40-59$ & 438 & $11 \%$ & 130 & $29.7 \%$ & 0.000 & 6.18 & 4.66 & 8.20 \\
\hline & $\geq 60$ & 244 & $6 \%$ & 110 & $45.1 \%$ & 0.000 & 12.03 & 8.74 & 16.54 \\
\hline \multirow[t]{2}{*}{ RDW (\%) } & $<14.5$ & 1647 & $43 \%$ & 128 & $7.8 \%$ & 0.000 & 1.00 & 0.00 & 0.00 \\
\hline & $\geq 14.5$ & 2204 & $57 \%$ & 459 & $20.8 \%$ & 0.000 & 3.12 & 2.54 & 3.84 \\
\hline \multirow[t]{4}{*}{ Phosphorus (mg/dl) } & $1.51<\mathrm{IP}<3.99$ & 2841 & $74 \%$ & 339 & $11.9 \%$ & 0.000 & 1.00 & 0.00 & 0.00 \\
\hline & $\leq 1.5$ & 49 & $1 \%$ & 14 & $28.6 \%$ & 0.001 & 2.95 & 1.57 & 5.54 \\
\hline & $4-4.49$ & 479 & $12 \%$ & 79 & $17.2 \%$ & 0.002 & 1.53 & 1.16 & 2.01 \\
\hline & $\geq 4.5$ & 482 & $13 \%$ & 155 & $32.2 \%$ & 0.000 & 3.50 & 2.80 & 4.37 \\
\hline \multirow[t]{4}{*}{ Magnesium (mg/dl) } & $1.35-2$ & 3136 & $81 \%$ & 406 & $12.9 \%$ & 0.000 & 1.00 & 0.00 & 0.00 \\
\hline & $\leq 1.35$ & 342 & $9 \%$ & 63 & $18.4 \%$ & 0.005 & 1.52 & 1.13 & 2.03 \\
\hline & $2-2.4$ & 347 & $9 \%$ & 105 & $30.3 \%$ & 0.000 & 2.92 & 2.27 & 3.75 \\
\hline & $\geq 2.4$ & 26 & $1 \%$ & 13 & $50 \%$ & 0.000 & 6.72 & 3.10 & 14.61 \\
\hline
\end{tabular}




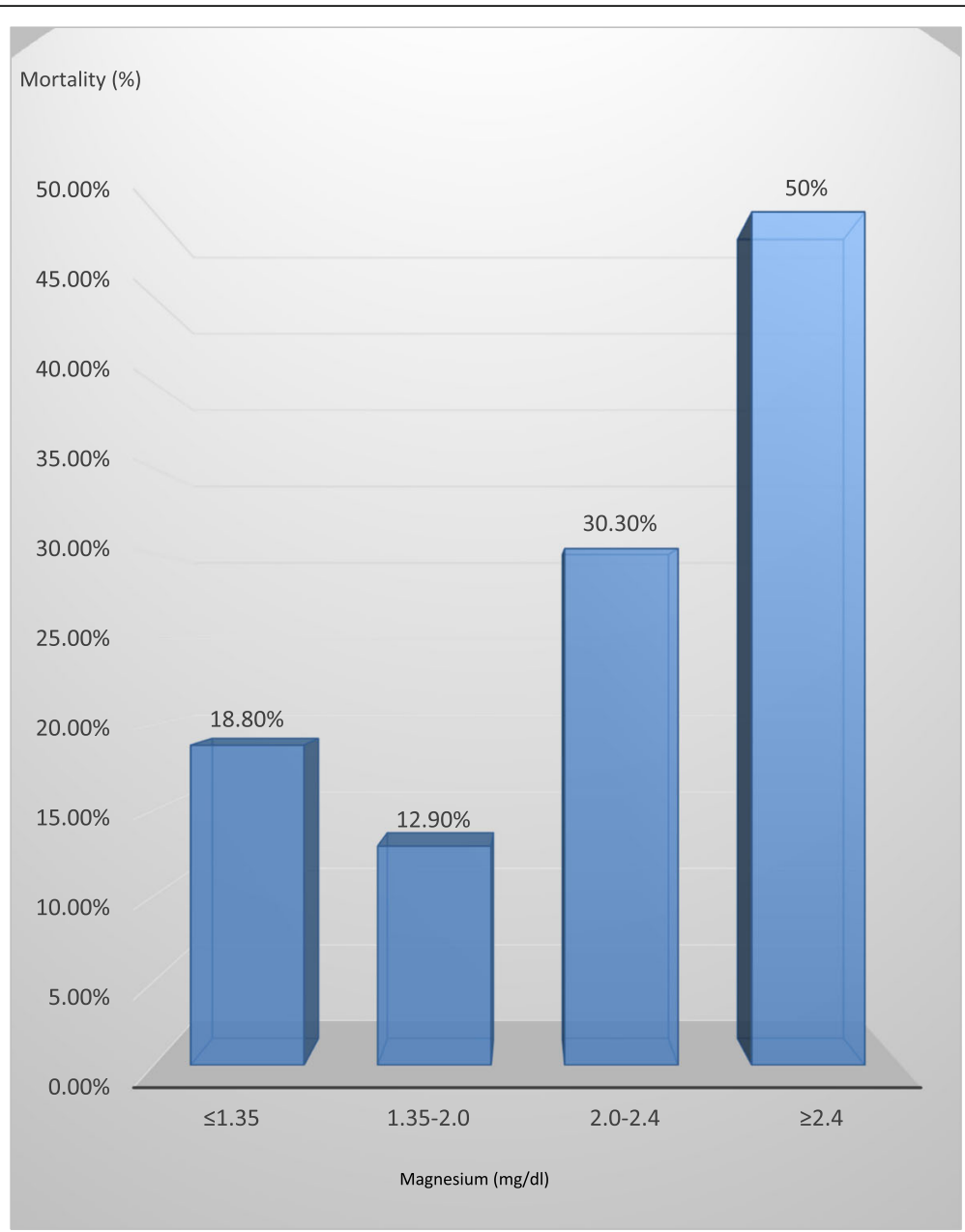

Fig. 130 days mortality according to magnesium levels

area under the curve for magnesium was 0.806 (95\% CI $0.787-0.825)$.

\section{Discussion}

In this retrospective study we studied the association between magnesium levels on admission and 30-day mortality in patients with community acquired pneumonia.

We found different 30-day mortality rates within the different magnesium levels: $18.8 \%$ in hypomagnesemia, $50 \%$ in hypermagnesemic, and $14.8 \%$ in normomagnesemic patients. This association was maintained even after adjustment for several parameters including albumin, BUN and age. Notably, magnesium levels within the upper normal limit, namely $(2-2.4 \mathrm{mg} / \mathrm{dl})$, were also associated with higher rates of 30-day mortality (30.3\%).

Magnesium is an intracellular cation that possesses various physiological functions. It functions as a co-factor in intracellular enzymatic activities especially by chelating intracellular anionic ligands. Magnesium also competes with calcium in binding sites on proteins and membranes. It is involved in other cell cycle related processes including
DNA and RNA synthesis, cell growth and reproduction, membrane structure, signal transduction modulation, and fat and protein synthesis [5, 13-15].

Magnesium deficiency is a common underdiagnosed problem in the ICU. Several studies have demonstrated high incidence of magnesium disturbances in ICU patients. Low Magnesium levels have been reported in approximately $50 \%$ of ICU patients. The morbidity and mortality rates were significantly higher in these patients compared to patients with normal magnesium rates [16-20]. Rubeiz et al. [18] reported a $46 \%$ mortality rates in patients with hypomagnesemia in ICU. Conceivably, there were two-fold increase in mortality rates among patient with hypomagnesemia as compared to those with normal levels. Thus, the conclusion was that patients admitted with hypomagnesemia in ICU have an excess mortality rates.

It is interesting to assume that supplementation of magnesium to CAP may improve outcome. Therefore, it is conceivable to plan a prospective study to examine magnesium as a therapeutic modality in addition to the accepted treatment of CAP. 
Table 2 The association between the different phosphorus and magnesium levels with 30-day mortality

\begin{tabular}{|c|c|c|c|c|c|c|c|c|c|}
\hline & & \multicolumn{2}{|l|}{ Total } & \multicolumn{2}{|c|}{30 day mortality } & \multirow[b]{2}{*}{$P$ value } & \multirow[b]{2}{*}{ OR } & \multirow{2}{*}{$\begin{array}{l}95 \% \mathrm{Cl} \\
\text { lower }\end{array}$} & \multirow[b]{2}{*}{ Upper } \\
\hline & & Number & Percent (\%) & Number & Percent \% & & & & \\
\hline Phosphorus (mg/dl) & Magnesium (mg/dl) & 3851 & & & & & & & \\
\hline \multirow[t]{4}{*}{$1.51-3.99$} & $1.35-2$ & 2370 & $62 \%$ & 245 & 10.3 & 0.000 & 1.00 & 0.00 & 0.00 \\
\hline & $\leq 1.35$ & 256 & $7 \%$ & 45 & 17.6 & 0.001 & 1.85 & 1.31 & 2.62 \\
\hline & $\geq 2$ & 215 & $6 \%$ & 49 & 22.8 & 0.000 & 2.56 & 1.81 & 3.62 \\
\hline & Other & 1010 & $26 \%$ & 248 & 24.6 & & . & . & \\
\hline \multirow[t]{4}{*}{$\leq 1.5$} & $1.35-2$ & 34 & $1 \%$ & 9 & 26.5 & 0.726 & 1.00 & 0.00 & 0.00 \\
\hline & $\leq 1.35$ & 13 & $0 \%$ & 5 & 38.5 & 0.424 & 1.74 & 0.45 & 6.71 \\
\hline & $\geq 2$ & 2 & $0 \%$ & 0 & 0.0 & 0.999 & 0.00 & 0.00 & 0.00 \\
\hline & Other & 3802 & $99 \%$ & 573 & 15.1 & . & . & . & . \\
\hline \multirow[t]{4}{*}{$\geq 4$} & $1.35-2$ & 698 & $18 \%$ & 148 & 21.2 & 0.000 & 1.00 & 0.00 & 0.00 \\
\hline & $\leq 1.35$ & 68 & $2 \%$ & 13 & 19.1 & 0.687 & 0.88 & 0.47 & 1.65 \\
\hline & $\geq 2$ & 153 & $4 \%$ & 69 & 45.1 & 0.000 & 3.05 & 2.12 & 4.40 \\
\hline & Other & 2932 & $76 \%$ & 357 & 12.2 & . & & & . \\
\hline \multirow[t]{4}{*}{$\geq 4.5$} & $1.35-2$ & 354 & $9 \%$ & 101 & 28.5 & 0.002 & 1.00 & 0.00 & 0.00 \\
\hline & $\leq 1.35$ & 34 & $1 \%$ & 9 & 26.5 & 0.799 & 0.90 & 0.41 & 2.00 \\
\hline & $\geq 2$ & 94 & $2 \%$ & 45 & 47.9 & 0.000 & 2.30 & 1.44 & 3.67 \\
\hline & Other & 3369 & $87 \%$ & 432 & 12.8 & & & & \\
\hline
\end{tabular}

Abbreviations: OR-odds ratio, Cl-confidence interval, IP-Inorganic Phosphorus, MG - Magnesium

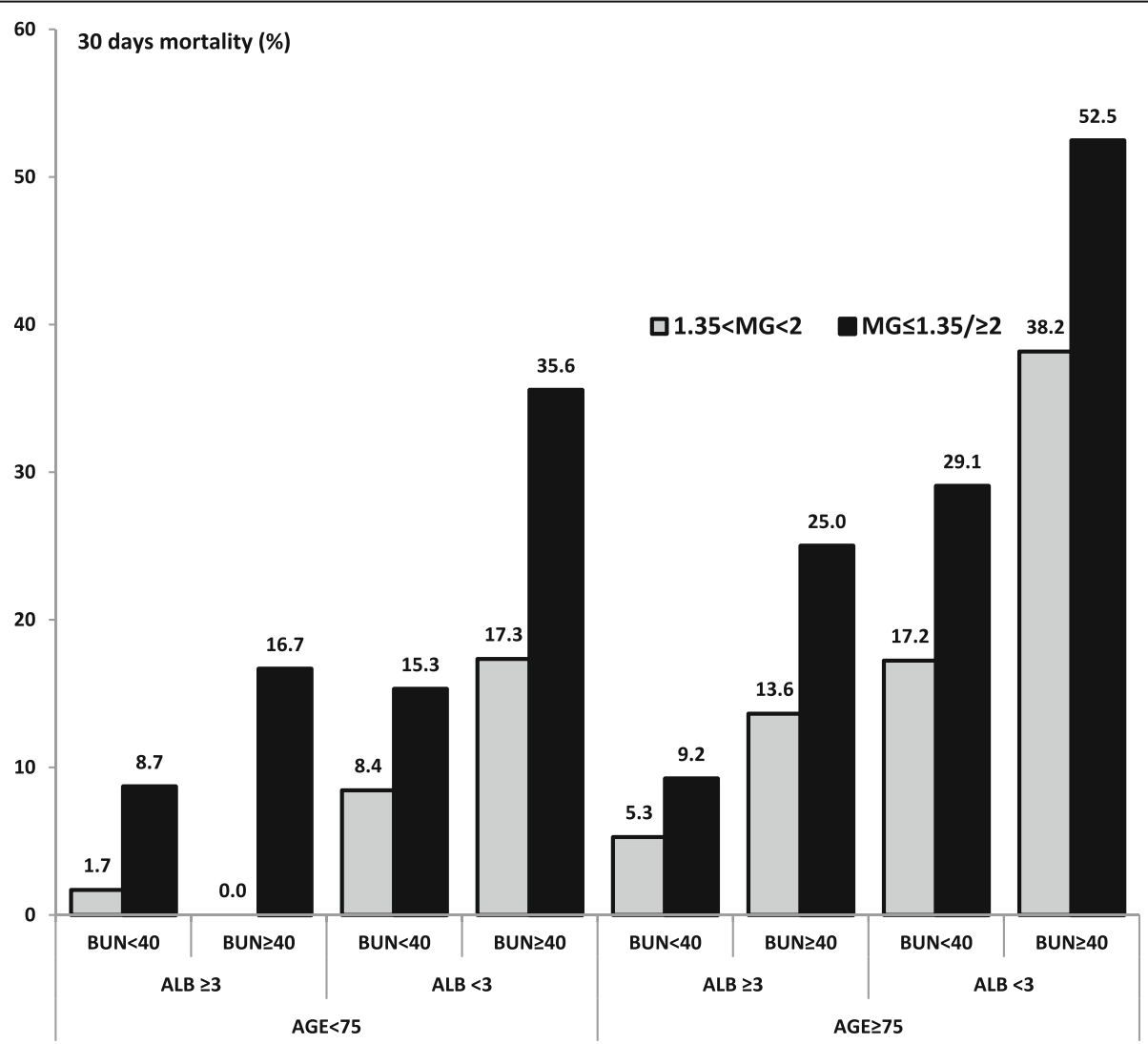

Fig. 2 The relationship between magnesium, age, albumin, BUN and 30-day mortality 
Table 3 Multivariate analysis of parameters associated with 30-day mortality

\begin{tabular}{|c|c|c|c|c|c|c|c|c|c|c|c|}
\hline \multirow[t]{3}{*}{ Variables } & & \multirow{3}{*}{$\begin{array}{l}\text { Coeff. } \\
\text { B }\end{array}$} & \multirow{3}{*}{$\begin{array}{l}\mathrm{P} \\
\text { value }\end{array}$} & \multirow{3}{*}{$\begin{array}{l}\text { Adjusted } \\
\text { OR }\end{array}$} & \multicolumn{7}{|c|}{ Bootstrap for variable in equation } \\
\hline & & & & & \multicolumn{2}{|c|}{ 95\% C.I.for OR } & \multirow[t]{2}{*}{ Bias } & \multirow{2}{*}{$\begin{array}{l}\text { Std. } \\
\text { Error }\end{array}$} & \multirow{2}{*}{$\begin{array}{l}P \\
\text { value }\end{array}$} & \multicolumn{2}{|c|}{$95 \% \mathrm{Cl}$ of $\mathrm{B}$} \\
\hline & & & & & Lower & Upper & & & & Lower & Upper \\
\hline \multirow[t]{3}{*}{ Albumin $(\mathrm{g} / \mathrm{dl})$} & $>3$ & & 0.00 & & & & & & & & \\
\hline & $2-3$ & 1.13 & 0.00 & 3.10 & 2.24 & 4.29 & -0.03 & 0.18 & 0.010 & 0.83 & 1.53 \\
\hline & $<2$ & 2.59 & 0.00 & 13.32 & 9.31 & 19.05 & 0.03 & 0.19 & 0.010 & 2.22 & 3.01 \\
\hline \multirow[t]{4}{*}{ BUN (mg/dl) } & $\leq 20$ & & 0.00 & & & & & & & & \\
\hline & $20-39$ & 0.57 & 0.00 & 1.77 & 1.37 & 2.29 & 0.02 & 0.14 & 0.010 & 0.28 & 0.92 \\
\hline & $40-59$ & 1.05 & 0.00 & 2.86 & 2.09 & 3.92 & 0.03 & 0.15 & 0.010 & 0.79 & 1.36 \\
\hline & $\geq 60$ & 1.28 & 0.00 & 3.61 & 2.49 & 5.24 & 0.01 & 0.20 & 0.010 & 0.97 & 1.72 \\
\hline Age (years) & $\geq 75$ & 0.93 & 0.00 & 2.53 & 1.98 & 3.22 & -0.00 & 0.11 & 0.010 & 0.60 & 1.18 \\
\hline Magnesium (mg/dl) & $\geq 2 / \leq 1.35$ & 0.63 & 0.00 & 1.87 & 1.42 & 2.48 & -0.01 & 0.11 & 0.010 & 0.27 & 0.91 \\
\hline Inoraganic phosphorous (mg/dl) & $\geq 4.5$ & 0.83 & 0.00 & 2.29 & 1.77 & 2.96 & 0.00 & 0.11 & 0.010 & 0.58 & 1.18 \\
\hline
\end{tabular}

Abbreviations: $O R$ odds ratio, $\mathrm{Cl}$ confidence interval, $B U N$ blood urea nitrogen

Hypermagnesemia, less frequently reported than hypomagnesemia, is found in $6-11 \%$ of patients admitted to ICU. It can also lead to cardiovascular and neuromuscular manifestations. The development of hypermagnesemia during the ICU stay is associated with higher morbidity and mortality rates and might be the direct result of prolonged disease, or sepsis $[11,21]$. Celi et al. found that hypermagnesemic patients had a 2.5 -fold greater likelihood of receiving intravenous vasopressors during the first 24 hours of ICU care, due to lower systemic blood pressure [22].Guerin et al. found that hypermagnesemia is associated with higher fatalities than hypomagnesemia [11]. Cheungpasitporn et al. found that respiratory diseases were associated with hypermagnesemia. This finding was probably attributed to magnesium mediated airway relaxation, immunomodulation and anti-inflammatory effects. Magnesium as an adjunctive therapy has been advocated for patients with moderate to severe airway diseases such as asthma despite inconclusive evidence of its benefit [23].

Magnesium is often given as a treatment of cardiac rhythm disturbances and status asthmaticus or for prevention of seizures and eclampsia [24, 25]. In the past, magnesium treatment was thought to be beneficial in treating ICU patients. This hypothesis was investigated by Broman et al. [13] who found that mild hypermagnesemia was associated with markedly worse survival parameters compared to normomagnesemic controls.

Our study has some limitations. First, is the retrospective nature of the study. It is important to emphasize that we did not have any influence on blood tests including magnesium levels which were taken according to the discretion of the treating physician. Secondly, our primary endpoint was all cause mortality. We did not have data regarding the specific cause of 30-day mortality. Third, data regarding that exact antibiotic agents prior to admission was missing in many patients. Therefore, we decided to exclude patients with prior antibiotic therapy. Fourth, data dealing with permanent medications were not available for many patients, with special emphasis on Proton Pump Inhibitors (PPI), a group of medication increasingly reported as a cause of hypomagnesemia. Fifth, the high mortality rates noticed in the study were due to selection bias since only hospitalized patients with pneumonia were included in the study.

\section{Conclusion}

In conclusion, in this cohort study of patients with CAP, we demonstrated that abnormal magnesium levels on admission may be associated with increased 30-day mortality rates, compared to normal levels. Being a simple and readily available blood test, we believe that magnesium levels on admission in patients with CAP may play, in conjugation with other scores such as PASI or CURB65, a valuable role in stratifying these patients on the basis of 30-day mortality. Prospectively, well-designed, comprehensive studies are necessary to validate our findings before making any practical conclusions. Whether magnesium disturbances play a causative role in 30-day mortality in patients with CAP, or just being a surrogate marker, is a question to be answered by prospective interventional studies designed to examine to effect of correcting these disturbances on the final outcome.

\section{Abbreviations}

AUC: Area Under Curve; BP: Systolic and diastolic blood pressure; BUN: Blood Urea Nitrogen; CAP: Community acquired pneumonia; Cl: Confidence intervals; Hb: Hemoglobin; HR: Heart rate; Mg: Magnesium; OR: Odds ratios; pCO2: Partial pressure of carbon dioxide; PSI: Pneumonia Severity Index; RDW: Red blood cell distribution width; RHCC: Rambam Health Care Campus; RR: Respiratory rate; SPSS: Statistics Products Solutions Services; WBC: White blood cell count

Acknowledgements

Not applicable. 


\section{Funding}

The authors declare they have not accepted any fundings.

\section{Availability of data and materials}

The datasets used and/or analysed during the current study are available from the corresponding author on reasonable request.

\section{Authors' contributions}

RN had full access to all of the data in the study and takes responsibility for the content of the manuscript, was involved in the conception, hypotheses delineation, and design of the study, acquisition and analysis of the data, in writing the article and in its revision prior to submission. MN, RN, TN, ZSA and EB were involved in the design of the study, hypotheses delineation, acquisition and analysis of the data, in writing the article and in its revision prior to submission. All authors have read and approved the final version of the manuscript.

\section{Ethics approval and consent to participate}

The Rambam Hospital Institutional Review Board approved the study. The approval number is 0597-16-RMB.

The need for informed consent was waived because of the retrospective, medical record-based design of the study.

\section{Consent for publication}

Not applicable - this study does not contain any patient personal details.

\section{Competing interests}

The authors declare they have no competing interests.

\section{Publisher's Note}

Springer Nature remains neutral with regard to jurisdictional claims in published maps and institutional affiliations.

\section{Author details}

'Department of Internal Medicine "B", Ramabm Health Care Campus, HaAliya HaShniya St 8, 3109601 Haifa, Israel. ${ }^{2}$ Rheumatology unit, Galilee Medical Center, Nahariya, Israel. ${ }^{3}$ Epidemiology and Biostatistics Unit, Rambam Health Care Campus, Haifa, Israel. ${ }^{4}$ The Rappaport's Faculty of Medicine, The Technion Institute, Haifa, Israel. ${ }^{5}$ Department of Internal Medicine " $\mathrm{H}$ ", Ramabm Health Care Campus, Haifa, Israel.

Received: 13 July 2018 Accepted: 17 December 2018

Published online: 27 December 2018

\section{References}

1. Trotter CL, Stuart JM, George R, Miller E. Increasing hospital admissions for pneumonia, England. Emerg Infect Dis. 2008;14(5):727-33 PubMed PMID: 18439353. Pubmed Central PMCID: 2600241. Epub 2008/04/29. eng.

2. Prina E, Ranzani OT, Torres A. Community-acquired pneumonia. Lancet. 2015;386(9998):1097-108 PubMed PMID: 26277247. Epub 2015/08/19. eng.

3. Regunath H, Oba Y. Pneumonia, community-acquired. 2017. PubMed PMID: 28613500. Epub 2017/06/15. eng.

4. Renaud B, Labarere J, Coma E, Santin A, Hayon J, Gurgui M, et al. Risk stratification of early admission to the intensive care unit of patients with no major criteria of severe community-acquired pneumonia: development of an international prediction rule. Crit Care. 2009;13(2):R54 PubMed PMID: 19358736. Pubmed Central PMCID: 2689501. Epub 2009/04/11. eng.

5. Swaminathan R. Magnesium metabolism and its disorders. Clin Biochem Rev. 2003;24(2):47-66 PubMed PMID: 18568054. Pubmed Central PMCID: 1855626. Epub 2008/06/24. eng.

6. Altura BM, Altura BT. Role of magnesium in patho-physiological processes and the clinical utility of magnesium ion selective electrodes. Scand J Clin Lab Invest Suppl. 1996;224:211-34 PubMed PMID: 8865438. Epub 1996/01/01. eng.

7. al-Ghamdi SM, Cameron EC, Sutton RA. Magnesium deficiency: pathophysiologic and clinical overview. Am J Kidney Dis. 1994;24(5):737-52 PubMed PMID: 7977315. Epub 1994/11/01. eng.

8. Dabbagh OC, Aldawood AS, Arabi YM, Lone NA, Brits R, Pillay M. Magnesium supplementation and the potential association with mortality rates among critically ill non-cardiac patients. Saudi Med J. 2006;27(6):821-5 PubMed PMID: 16758043. Epub 2006/06/08. eng.
9. Safavi M, Honarmand A. Admission hypomagnesemia--impact on mortality or morbidity in critically ill patients. Middle East J Anaesthesiol. 2007;19(3): 645-60 PubMed PMID: 18044292. Epub 2007/11/30. eng.

10. Sanders GT, Huijgen HJ, Sanders R. Magnesium in disease: a review with special emphasis on the serum ionized magnesium. Clin Chem Lab Med. 1999;37(11-12):1011-33 PubMed PMID: 10726809. Epub 2000/03/22. eng.

11. Guerin C, Cousin C, Mignot F, Manchon M, Fournier G. Serum and erythrocyte magnesium in critically ill patients. Intensive Care Med. 1996; 22(8):724-7 PubMed PMID: 8880238. Epub 1996/08/01. eng.

12. Naffaa ME, Mustafa M, Azzam M, Nasser R, Andria N, Azzam ZS, et al. Serum inorganic phosphorus levels predict 30-day mortality in patients with community acquired pneumonia. BMC Infect Dis. 2015;15:332 PubMed PMID: 26268323. Pubmed Central PMCID: 4535260. Epub 2015/08/14. eng.

13. Broman M, Hansson F, Klarin B. Analysis of hypo- and hypermagnesemia in an intensive care unit cohort. Acta Anaesthesiol Scand. 2018:16 PubMed PMID: 29341068

14. Huijgen HJ, Soesan M, Sanders R, Mairuhu WM, Kesecioglu J, Sanders GT. Magnesium levels in critically ill patients. What should we measure? Am J Clin Pathol. 2000;1 14(5):688-95 PubMed PMID: 11068541.

15. Escuela MP, Guerra M, Anon JM, Martinez-Vizcaino V, Zapatero MD, GarciaJalon A, et al. Total and ionized serum magnesium in critically ill patients. Intensive Care Med. 2005;31(1):151-6 PubMed PMID: 15605229.

16. Chernow B, Smith J, Rainey TG, Finton C. Hypomagnesemia: implications for the critical care specialist. Crit Care Med. 1982;10(3):193-6 PubMed PMID: 7037303.

17. Reinhart RA, Desbiens NA. Hypomagnesemia in patients entering the ICU. Crit Care Med. 1985;13(6):506-7 PubMed PMID: 3996005.

18. Chen $M$, Sun $R$, Hu B. The influence of serum magnesium level on the prognosis of critically ill patients. Zhonghua wei zhong bing ji jiu yi xue. 2015;27(3):213-7 PubMed PMID: 25757972.

19. Thongprayoon C, Cheungpasitporn W, Erickson SB. Admission hypomagnesemia linked to septic shock in patients with systemic inflammatory response syndrome. Ren Fail. 2015;37(9):1518-21 PubMed PMID: 26335852.

20. Upala S, Jaruvongvanich V, Wijarnpreecha K, Sanguankeo A. Hypomagnesemia and mortality in patients admitted to intensive care unit: a systematic review and meta-analysis. QJM. 2016;109(7):453-9 PubMed PMID: 27016536

21. El Said SM, Aly WW. Magnesium levels among critically ill elderly patients; mortality and morbidity correlation. Adv in Aging Res. 2014;Vol. 03(01):6.

22. Celi LA, Scott DJ, Lee J, Nelson R, Alper SL, Mukamal KJ, et al. Association of hypermagnesemia and blood pressure in the critically ill. J Hypertens. 2013; 31(11):2136-41 discussion 41. PubMed PMID: 24029865. Pubmed Central PMCID: 5682028.

23. Cheungpasitporn W, Thongprayoon C, Qian Q. Dysmagnesemia in hospitalized patients: prevalence and prognostic importance. Mayo Clin Proc. 2015;90(8):1001-10 PubMed PMID: 26250725

24. Manrique AM, Arroyo M, Lin Y, El Khoudary SR, Colvin E, Lichtenstein S, et al. Magnesium supplementation during cardiopulmonary bypass to prevent junctional ectopic tachycardia after pediatric cardiac surgery: a randomized controlled study. J Thorac Cardiovasc Surg. 2010;139(1):162-9 e2 PubMed PMID: 19819469

25. Schuh S, Sweeney J, Freedman SB, Coates AL, Johnson DW, Thompson G, et al. Magnesium nebulization utilization in management of pediatric asthma (MagNUM PA) trial: study protocol for a randomized controlled trial. Trials. 2016;17(1):261 PubMed PMID: 27220675. Pubmed Central PMCID: 4879727.

Ready to submit your research? Choose BMC and benefit from:

- fast, convenient online submission

- thorough peer review by experienced researchers in your field

- rapid publication on acceptance

- support for research data, including large and complex data types

- gold Open Access which fosters wider collaboration and increased citations

- maximum visibility for your research: over $100 \mathrm{M}$ website views per year

At BMC, research is always in progress.

Learn more biomedcentral.com/submission 